\title{
Prenatal risk factors and occurrence of allergic rhinitis among elementary school children in an urban city
}

\author{
Szu-Pin Hsu ${ }^{a}$, Kai-Nan Lin ${ }^{b}$, Ching-Ting Tan ${ }^{b}$, Fei-Peng Lee ${ }^{c}$, Hung-Meng Huang ${ }^{a, *}$ \\ a Department of Otolaryngology, Taipei City Hospital, Taipei Medical University, Taipei, Taiwan \\ ${ }^{\mathrm{b}}$ Department of Otolaryngology, National Taiwan University Hospital and National Taiwan University College of Medicine, Taipei, Taiwan \\ ${ }^{\mathrm{c}}$ Department of Otolaryngology, Taipei Medical University Hospital and Taipei Medical University, Taipei, Taiwan
}

\section{A R T I C L E I N F O}

\section{Article history:}

Received 3 November 2008

Received in revised form 10 February 2009

Accepted 12 February 2009

Available online 31 March 2009

Keywords:

Risk factor

Allergic rhinitis

\begin{abstract}
A B S T R A C T
Objectives: To investigate the incidence and prenatal risk factors for allergic rhinitis among elementary school children in an urban city.

Study design: Risk factor data were collected by questionnaire and direct physical examination. Multiple logistic regression analysis was used to calculate the odds ratios of developing allergic rhinitis among children 6-13 years of age.

Methods: From January 2006 to December 2006, we enrolled 1368 elementary school children in the study. Sampling was done by a multi-stage clustered-stratified random method to determine the study subject. All the children studied attended 12 elementary schools located in the six districts in Taipei, with two schools in each district. Odds ratios were adjusted for the confounding effects of gender, parity, maternal age at childbirth, maternal education, gestational complications, tobacco smokers in the residence, pets, carpets, molds, and air pollution.

Results: The incidence of allergic rhinitis in the study was $50.1 \%(685 / 1368)$. Factors like gender $(p<.001)$, parity $(p<.05)$, carpets $(p<.025)$, and air pollution $(p<.001)$ increased risk, while the other factors did not $(p>.05$ for all).

Conclusion: Gender, parity, carpets, and air pollution increased the risk of developing allergic rhinitis among elementary school children. Other potential factors such as low birth weight, maternal age at childbirth, parental education, gestational complications, presence of tobacco smokers, and exposure to pets and molds did not significantly increase risk of developing allergic rhinitis.
\end{abstract}

(c) 2009 Elsevier Ireland Ltd. All rights reserved.

\section{Introduction}

Allergic rhinitis is characterized clinically by the presence of sneezing or itching, nasal blockage, and rhinorrhea [1]. The causes of childhood allergic rhinitis and other atopic diseases are largely unexplained [2], and it is becoming increasingly apparent that the atopic phenotype frequently begins early in life, even before birth [3]. The higher prevalence of allergic rhinitis in people living in developed countries suggests a significant relationship between allergens and the environment [4]. Therefore, allergic rhinitis may be a multifactorial disease, whose expression is dependent on both familial and environmental factors.

To date, the mechanism and immunological aspects of allergy have been studied [5,6], but the host and environment risk factors

\footnotetext{
* Corresponding author at: Department of Otorhinolaryngology, Taipei City Hospital, Taipei Medical University, 12 Fu Chou Street, ->Taipei->, ->Taiwan->. Tel.: +886 2 23916471x1235; fax: +1 886227979497.

E-mail address: hmengh@yahoo.com.tw (H.-M. Huang).
}

related to the expression of childhood allergic rhinitis are poorly understood [7]. The aim of our study was to investigate the incidence and the prenatal risk factors of allergic rhinitis among elementary school children in an urban city.

\section{Materials and methods}

From January 2006 to December 2006, we surveyed 1927 elementary school children. Sampling was done by a multi-stage clustered-stratified random method based on the data obtained from Taipei Education Bureau to determine the study subject. All of the children studied attended 12 of the 151 elementary schools located in six districts in Taipei, with two schools in each district. One class was randomly chosen from each of the 6 grades in the 12 schools, with 1927 children in total. A team of six otolaryngologists visited 12 elementary schools in the sampling frame to obtain information by physical examination and structured, self-administered questionnaire filled in by the mother. Of the target population, 154 children were excluded from the study due to suffering from colds and 405 children were excluded from the 
study due to incomplete record of the questionnaire. The actual number of children enrolled was 1368 ( 728 boys and 640 girls) from 12 elementary schools. The children ranged in age from 6 to 13 years (median, 11.7 years). Additional information on birth weight and other demographic factors were drawn from the Ministry of Internal Affairs. Written informed consent for participation in the study was provided by all the guardians.

The nasal cavities of the participants were examined using a 4.0- $\mathrm{mm}, 30^{\circ}$ endoscope. Allergic rhinitis was defined as the presence of typical nasal symptoms including watery rhinorrhea, sneezing, and nasal obstruction of more than 12 months' duration, positive history of known allergen or triggering factors, and pale nasal mucosa.

Multiple logistic regression analysis was done using SAS software (version 8.2) to adjust for the effects of the independent variables studied. The odds ratios were adjusted for the confounding effects of gender, parity, maternal age at childbirth, parental education, gestational complications, tobacco smokers, pets, carpets, molds, and air pollution.

\section{Results}

The overall incidence of allergic rhinitis in our study population was $50.1 \%$ (685/1368). The distributions of population characteristics of the 1368 elementary school children studied are illustrated in Table 1 . The distributions of environment-related disease characteristics among the 1368 elementary school children studied are illustrated in Table 2.

The odds ratios were adjusted for the confounding effects of gender, parity, maternal age at birth, maternal education, gestational complications, tobacco smokers in the residence, pets, carpets, molds, and air pollution. Gender and parity were significant risk factors for developing allergic rhinitis (Table 3). Other host factors included birth weight, maternal age at birth, gestation age, gestational complications (bleeding, placenta privia, toxemia, lower abdominal pain during pregnancy, and pregnancy diabetes mellitus), maternal education, and paternal education; these factors showed no significant correlation with allergic rhinitis ( $p>.05$ for all).

Air pollution and presence of carpets in the home were significant risk factors for allergic rhinitis (Table 3 ), while other environmental factors such as tobacco smokers in the home, and exposure to pets, and molds had no significant correlation with allergic rhinitis ( $p>.05$ for all).

\section{Discussion}

The incidence of allergic rhinitis was 50.1\% (685/1368) among the elementary school children in this Taipei in the study. The incidence of allergic rhinitis in Taipei was higher than other reports, such as the $1.14 \%$ children and adults with perennial allergic rhinitis in a Korean report [8], 13.5\% of Switzerland adults [9], $26.3 \%$ of American college students [4]. In 1999, Nimmagadda and Evans [10] reported that the incidence of allergic rhinitis in children is increasing rapidly, roughly doubling over the past decade.

It is reported that residents in urban areas have an increased prevalence of allergic rhinitis and asthma compared to rural areas $[11,12]$. Min et al. [8] also reported that a geographical difference was noted, with higher rates in urban cities. The higher incidence of allergic rhinitis in our study could be explained by Huang and Liu's report that allergic rhinitis with a positive skin reaction and positive radioallergosorbent test to Dermatophagoides pteryssimus or D. fabrinae is common among Taiwanese patients [13]. It is also consistent with the significantly higher prevalence of allergic rhinitis among the children in our study who are exposed to carpets. Furthermore, Taipei is an urban city.
Table 1

Distribution of population characteristics in elementary school age among 1368 subjects born in Taipei.

\begin{tabular}{|c|c|}
\hline Population characteristics & $\begin{array}{l}\text { Percentage of } \\
\text { total population (\%) }\end{array}$ \\
\hline \multicolumn{2}{|l|}{ Gender } \\
\hline Male & 52.3 \\
\hline Female & 47.7 \\
\hline \multicolumn{2}{|l|}{ Birth weight (g) } \\
\hline$<2500$ & 13.9 \\
\hline$\geq 2500$ & 86.1 \\
\hline \multicolumn{2}{|l|}{ Maternal age at childbirth (y/o) } \\
\hline$\leq 25$ & 20.2 \\
\hline $26-35$ & 76.9 \\
\hline$\geq 36$ & 2.9 \\
\hline \multicolumn{2}{|l|}{ Gestation age (weeks) } \\
\hline$<37$ & 12.9 \\
\hline$\geq 37$ & 87.1 \\
\hline \multicolumn{2}{|l|}{ Gestational complication } \\
\hline Non-disease & 95.8 \\
\hline Disease & 4.2 \\
\hline \multicolumn{2}{|l|}{ Parity } \\
\hline$N=1$ & 47.3 \\
\hline$N=2$ & 37.6 \\
\hline$N \geq 3$ & 15.1 \\
\hline \multicolumn{2}{|l|}{ Maternal education } \\
\hline$\leq$ Senior high school & 57.9 \\
\hline$\geq$ Junior college or university & 42.1 \\
\hline \multicolumn{2}{|l|}{ Paternal education } \\
\hline$\leq$ senior high school & 49.7 \\
\hline$\geq$ Junior college or university & 50.3 \\
\hline \multicolumn{2}{|l|}{ Maternal age $(\mathrm{y} / \mathrm{o})$} \\
\hline$\leq 25$ & 5.8 \\
\hline $26-35$ & 25.2 \\
\hline$\geq 36$ & 69.1 \\
\hline \multicolumn{2}{|l|}{ Paternal age $(y / 0)$} \\
\hline$\leq 25$ & 5.6 \\
\hline $26-35$ & 10.6 \\
\hline$\geq 36$ & 83.8 \\
\hline \multicolumn{2}{|l|}{ Allergic rhinitis } \\
\hline Non-disease & 49.9 \\
\hline Disease & 50.1 \\
\hline
\end{tabular}

Table 2

Distribution of environment-related disease characteristics in elementary school age among 1368 subjects born in Taipei.

\begin{tabular}{ll}
\hline $\begin{array}{l}\text { Environment-related } \\
\text { disease characteristics }\end{array}$ & $\begin{array}{l}\text { Percentage of total } \\
\text { population (\%) }\end{array}$ \\
\hline Pets & 84.9 \\
$\quad$ Non-exposure & 15.1 \\
Exposure & \\
Carpets & 91.0 \\
$\quad$ Non-exposure & 9.0 \\
Exposure & \\
Molds & 82.9 \\
$\quad$ Non-exposure & 15.1 \\
Exposure & \\
Surrounding tobacco smokes & 47.8 \\
Non-exposure & 52.2 \\
Exposure & \\
Air pollutions & 76.7 \\
Non-exposure & 23.3 \\
Exposure &
\end{tabular}


Table 3

Adjusted odds ratios and 95\% confidence intervals for allergic rhinitis in elementary school age by gender, birth weight, parity, maternal age at childbirth, maternal education, gestational complications, surrounding tobacco smokers, pets, carpets, molds, air pollutions for 1368 subjects born in Taipei.

\begin{tabular}{|c|c|c|}
\hline Variables & $\begin{array}{l}\text { Adjusted } \\
\text { odds ratios }\end{array}$ & $\begin{array}{l}95 \% \text { confidence } \\
\text { intervals }\end{array}$ \\
\hline \multicolumn{3}{|l|}{ Birth weight } \\
\hline$<2500$ & 1.296 & $0.887-1.895$ \\
\hline$\geq 2500$ & 1.00 & \\
\hline \multicolumn{3}{|l|}{ Gender } \\
\hline Female & $1.718^{* * *}$ & $1.383-2.135^{*}$ \\
\hline Male & 1.00 & \\
\hline \multicolumn{3}{|l|}{ Parity } \\
\hline$N=1$ & $1.418^{*}$ & $1.023-1.965^{*}$ \\
\hline$N=2$ & $1.431^{*}$ & $1.012-2.006^{*}$ \\
\hline$N \geq 3$ & 1.00 & \\
\hline \multicolumn{3}{|l|}{ Maternal age at childbirth } \\
\hline$\leq 25$ & 0.880 & $0.663-1.169$ \\
\hline $26-35$ & 1.00 & \\
\hline$\geq 36$ & 0.956 & $0.513-1.781$ \\
\hline \multicolumn{3}{|l|}{ Maternal education } \\
\hline$\leq$ Senior high school & 1.00 & \\
\hline$\geq$ Junior college or university & 0.986 & $0.787-1.235$ \\
\hline \multicolumn{3}{|l|}{ Gestational complication } \\
\hline Non-disease & 1.00 & \\
\hline Disease & 1.024 & $0.612-1.715$ \\
\hline \multicolumn{3}{|l|}{ Surrounding tobacco smokes } \\
\hline Non-exposure & 1.00 & \\
\hline Exposure & 0.837 & $0.673-1.041$ \\
\hline \multicolumn{3}{|l|}{ Pets } \\
\hline Non-exposure & 1.00 & \\
\hline Exposure & 1.140 & $0.840-1.547$ \\
\hline \multicolumn{3}{|l|}{ Carpets } \\
\hline Non-exposure & 1.00 & \\
\hline Exposure & $1.598^{*}$ & $1.087-2.348$ \\
\hline \multicolumn{3}{|l|}{ Molds } \\
\hline Non-exposure & 1.00 & \\
\hline Exposure & 1.298 & $0.963-1.750$ \\
\hline \multicolumn{3}{|l|}{ Air pollutions } \\
\hline Non-exposure & 1.00 & \\
\hline Exposure & $1.438^{* *}$ & $1.099-1.881^{*}$ \\
\hline
\end{tabular}

For the evaluation of risk factors, all potential factors were divided into environmental and host factors. Environmental factors included air pollution, smokers in the residence, and exposure to carpets, pets, and molds. Host factors were parent's gender, maternal age at birth, maternal education, birth weight, and gestational complications. Paul et al. [14] reported that nonspecific atmospheric pollutants such as ozone, $\mathrm{SO}_{2}$ or $\mathrm{NO}_{2}$ gas or particles of burnt fuels may contribute to sensitization of people to allergic rhinitis [14]. In our study, we found significant correlation between air pollution and allergic rhinitis. The result in the study is in agreement with the report by Paul et al. [14]. Although smoking is reportedly related to allergic rhinitis, some literature recently reported little correlation between smoking or passive smoking and allergic rhinitis $[8,15,16]$. We found little correlation between smoke and allergic rhinitis. Other potential risk factors, such as molds and pets did not significantly influence the incidence in developing allergic rhinitis in our study.

Parity represents the number of siblings borne of one woman. Possessing more siblings increases the opportunities for contracting infections, and infections occurring in early life, perhaps, specifically at the time of first exposure to relevant allergens, could inhibit the proliferation of Th2 cell clones and thereby prevent allergy [17]. Xu et al. [7] reported that having more older siblings appears to be a protective factor as far as childhood allergic disorders such as rhinitis are concerned. Our results are consistent with those of other studies [7,17]. Turkelaub and Gergen found that females reported more allergic rhinitis than males in their study of 12,743 adults [11]. Yamatomo et al reported that sex is responsible for the production of antigen-specific Ig E and that androgen appears to decrease the production of specific Ig E in male mice [18]. In our study, girls also had a significantly higher rate of allergic rhinitis compared to boys.

Low birth weight is one of the factors that determine respiratory health in later childhood [19]. Frischer et al. [20] reported that asthma was significantly more prevalent among children with birth weights less than $2500 \mathrm{~g}$; however, no significant correlation was observed between low birth weight and the occurrence of allergic rhinitis in our study. Since the numbers of subjects in both studies were small, further studies with greater numbers of subjects and greater detail in the stratification of birth weights are necessary to clarity this issue. Several studies report a greater asthma or allergic disease rates in higher socioeconomic classes [20,21], but others reported no such association $[9,22]$. We used parental education to represent socioeconomic class in our study; both maternal and paternal educational levels showed no significant correlations with allergic rhinitis. The differences in results could be due to dissimilar social structures, or sets of exposures in different populations. Xu et al. reported that allergic rhinitis was more prevalent in children whose mothers reported bleeding in the first trimester [7], but our study found that gestational complications had no influence on allergic rhinitis.

One of the limitations of our study was the diagnosis of allergic rhinitis by subjective symptoms and nasoendoscopic findings without performing a skin test, compared to other report [4]. It may lead to a higher prevalence of allergic rhinitis in the study.

\section{Conclusion}

The overall prevalence of allergic rhinitis was $50.1 \%(685 / 1368)$ in Taipei. The results of the study suggest that allergic rhinitis was influenced by several risk factors such as gender, parity, presence of carpets in the home, and air pollution.

\section{References}

[1] A.L. Wright, C.J. Holberg, M. Halonen, F.D. Martinez, W. Morgan, L.M. Taussig, Epidemiology of physician-diagnosed allergic rhinitis in childhood, Pediatrics 94 (1994) 895-901.

[2] M.A. Brown, A.J. Halonen, Cutting the cord: is birth already too late for primary prevention of allergy? Clin. Exp. Allergy 27 (1997) 4-6.

[3] J.A. Warner, A.C. Jones, E.A. Miles, J.O. Warner, Prenatal sensitization, Pediatr. Allergy Immunol. 7 (Suppl. 9) (1996) 98-101.

[4] G.W. Hagy, G.A. Settipane, Bronchial asthma, allergic rhinitis and allergy skin test among college students, J. Allergy 44 (1969) 323-332.

[5] F.M. Baroody, Allergic rhinitis: broader disease effects and implications for management, Otolaryngol. Head Neck Surg. 128 (2003) 616-631.

[6] J.H. Krouse, Seasonal and perennial rhinitis, in: J.H. Krouse, S.J. Chadwick, B.R. Gordon, et al. (Eds.), Allergy and Immunology: An Otolaryngic Approach, Lippincott, Williams \& Wilkins, Philadelphia, 2002, pp. 209-220.

[7] B. Xu, M.R. Jarvelin, J. Pekkanen, Prenatal factors and occurrence of rhinitis and eczema among offspring, Allergy 54 (1999) 829-836.

[8] Y.G. Min, H.W. Jung, H.S. Kim, S.K. Park, K.Y. Yoo, Prevalence and risk factors for perennial allergic rhinitis in Korea: results of a nationwide survey, Clin. Otolaryngol. 22 (1997) 139-144.

[9] B. Wuthrich, C. Schindler, P. Leuenberger, L.U. Ackermann, Prevalence of atopy and pollinosis in the adult population of Switzerland, Int. Arch. Allergy Immunol. 106 (1995) 149-156.

[10] S.R. Nimmagadda, R. Evans 3rd., Allergy: etiology and epidemiology, Pediatr. Rev. 20 (1999) 111-115.

[11] P.C. Turkelaub, P.J. Gergen, Prevalence of upper and lower respiratory conditions in the US population by social an environmental factors, Ann. Allergy 67 (1991) $147-154$. 
[12] T. Antova, The effect of air pollution on the allergic reactivity of the population, Probl. Klig. 18 (1993) 20-31.

[13] H.M. Huang, C.M. Liu, Immunotherapy for allergic rhinitis, J. Taiwan Otolaryngol. Head Neck Surg. 27 (1992) 52-56.

[14] G. Paul, J.C. Bessot, E. Quoix, Effect of the environment on the development of respiratory allergies, Rev. Pneumol. Clin. 45 (1989) 231-236.

[15] W. Popp, H. Rauscher, K. Serti, T. Wanke, H. Zwick, Risk factors for sensitization to furred pets, Allergy 45 (1990) 75-79.

[16] T.P. Ng, W.C. Tan, Epidemiology of allergic rhinitis and its associated risk factors in Singapore, Int. J. Epidemiol. 23 (1994) 553-558.

[17] F.D. Martinez, Role of viral infections in the inception of asthma and allergies during childhood: could they be protective? Thorax 49 (1994) 1189-1191.
[18] T. Yamatomo, M. Okano, T. Ono, E. Nakayama, T. Yoshino, A.R. Satoskar, et al., Sexrelated differences in the initiation of allergic rhinitis in mice, Allergy 56 (2001) 523-531.

[19] K.N. Chan, A. Elliman, E. Bryan, M. Silverman, Respiratory symptoms in children of low birthweight, Arch. Dis. Child 64 (1989) 1294-1304.

[20] T. Frischer, J. Kuehr, R. Meinert, W. Karmaus, R. Barth, E. Hermann-Kunz, Relationship between low birth weight and respiratory symptoms in a cohort of primary school children, Acta Padiatr. 81 (1992) 1040-1041.

[21] E. Von Mutius, F.D. Martinez, C. Fritzsch, T. Nicolai, G. Roell, H.H. Thiemann, Prevalence of asthma and atopy in two areas of West and East Germany, Am. J Respir. Crit. Care Med. 149 (1994) 358-364.

[22] L.J. Horwood, D.M. Fergusson, F.T. Shannon, Social and familial factors on the development of early childhood asthma, Pediatrics 75 (1985) 859-868. 